\title{
Developmental Competence of Embryos Derived from Reciprocal In Vitro Fertilization between Yak (Bos grunniens) and Cattle (Bos taurus)
}

\author{
Xiang-Dong ZI ${ }^{1)}$, Rong-Hua YIN1), Shao-Wei CHEN1), Guan-Nan LIANG'), Da-Wei ZHANG') \\ and Chun-Hua GUO')
} 1) The Key Laboratory of Animal Genetics and Breeding, Ministry of Education and State Ethnic Affairs Commission,
Southwest University for Nationalities, Sichuan 610041, China

\begin{abstract}
The purpose of this study was to investigate fertilization ability and embryo development to the blastocyst stage after reciprocal in vitro fertilization (IVF) between yak and cattle in an attempt to clarify the problem of low conception rate after mating yak females with cattle bulls. In vitro-matured (IVM) cattle and yak oocytes were inseminated with either Holstein or yak spermatozoa, and after an 18-h of coincubation period, a proportion of the oocytes was fixed and examined for sperm penetration, polyspermy and male pronuclear formation. The remaining oocytes were cultured in vitro and evaluated for cleavage and blastocyst formation rates. The percentage of IVM oocytes penetrated by spermatozoa ranged from 78.5 to $90.5 \%$, and the formation of one or two pronuclei and the incidence of polyspermy did not differ among the different combinations. The cleavage and blastocyst rates were not affected by the species of the sperm, but they were affected by the species of the oocytes $(\mathrm{P}<0.05)$, with cattle oocytes having a higher $(\mathrm{P}<0.05)$ cleavage and blastocyst rates $(69.9$ and $31.3 \%)$ than yak oocytes $(62.7$ and $11.5 \%)$. The blastocyst formation rate was calculated from the cleaved zygotes. The interaction between sire and oocytes species $(\mathrm{P}<0.05)$ influenced blastocyst formation rate, with the highest blastocyst rate occurring in cattle oocytes fertilized with yak spermatozoa $(36.5 \%)$ and the lowest rate occurring in yak oocytes fertilized with yak spermatozoa (9.4\%). The effect of heterosis was apparent at the blastocyst stage, but there was a large reciprocal difference in blastocyst production between crosses. It was concluded that the low conception rate that results from crossing yaks with cattle is not due to either a speciesspecific block of fertilization or the developmental competence of the early stage embryo.
\end{abstract}

Key words: Cattle, Early development, Embryos, In vitro fertilization (IVF), Yak

(J. Reprod. Dev. 55: 480-483, 2009)

$\mathbf{T}$ he yak is one of the world's most remarkable domestic animals - a herbivore living on the "roof of the world", in and around the Himalayas and further north at altitudes ranging from 2500 to $5500 \mathrm{~m}$ with no frost-free period and mostly above the tree line. They are very important to local people for meat, milk and draft power given that few other animals survive in these areas. However, their production traits are inferior to those of improved cattle (Bos taurus) breeds [1, 2].

Interest in the commercial use of local cattle $\times$ yak hybrids has existed for at least 3000 years. During this time, attempts have been made to improve meat and milk production (quoted from Wiener et al. [1]). A number of systematic studies carried out from 1950s to 1990s have examined the meat and milk performance of hybrids of yak derived from both natural mating and artificial insemination using semen from exotic breeds of cattle such as the Holstein, Simmental, Hereford and Shorthorn. The results have shown that F1 hybrids from dairy cattle breeds produce 100-300\% more milk than the yak [3, 4]. However, the cost-effectiveness of such hybridization remains debatable for several reasons. First, there is a marked difference between the pregnancy rates of purebred yaks $(>70 \%)$ compared with hybrid animals $(<30 \%)[3,5]$, but the causes of this difference have not been well studied at the gamete and embryo levels. Second, the mean birth weight of hybrid yaks is

Accepted for publication: April 27, 2009

Published online in J-STAGE: June 11, 2009

Correspondence: X-D Zi (e-mail: zixd2000@yahoo.com) much higher than that of purebred yak calves, and this results in a higher incidence of dystocia in the former group [1]. Third, sterility of F1 males prevents successful inter-se matings. F1 hybrid females can be mated back to yak or cattle bulls, but the poor performance of progeny (both meat and milk) makes backcross generations commercially unattractive. Since F1 females have a larger body size and a normal or improved reproductive performance compared with the purebred yak, they should be ideal recipients of hybrid F1 embryos. In this way, the F1 hybrid females would not only give additional milk, but also produce valuable offspring (F1).

During the past decades, embryo transfer in farm animals has continued to make major strides and now includes transfer of in vitro produced (IVP) embryos [6-8]. However, the efficiency of this procedure in the yak has been relatively poor [9-11]. Therefore, the objective of this study was to investigate fertilization ability and embryo development to the blastocyst stage after reciprocal in vitro fertilization (IVF) between yak and cattle in order to understand the low conception rate after mating yak females with cattle bulls.

\section{Materials and Methods}

\section{Materials}

Dulbecco's phosphate-buffered saline (DPBS) was purchased from Hyclone Laboratories, Inc. (Logan, UT, USA), Folltropin 
Table 1. Fertilization status of putative zygotes produced in vitro from different combinations of yak and cattle gametes

\begin{tabular}{|c|c|c|c|c|c|}
\hline Species combination & No. oocytes & No. (\%) $1 \mathrm{PN}^{*}$ & No. (\%) 2 PN & No. $(\%)>2$ PN & No. (\%) penetrated \\
\hline Yak $9+$ × yak ${ }^{7}$ & 79 & $1^{\mathrm{a}}(1.3)$ & $52^{\mathrm{a}}(65.8)$ & $12^{\mathrm{a}}(15.2)$ & $65^{\mathrm{a}, \mathrm{b}}(82.3)$ \\
\hline Yak $9 \times$ cattle $\sigma^{\zeta}$ & 93 & $1^{\mathrm{a}}(1.1)$ & $64^{\mathrm{a}}(66.8)$ & $8^{a}(8.6)$ & $73^{\mathrm{a}}(78.5)$ \\
\hline Cattle 우 × yak ơ & 84 & $0^{\mathrm{a}}(0.0)$ & $64^{\mathrm{a}}(76.2)$ & $12^{\mathrm{a}}(14.3)$ & $76^{\mathrm{b}}(90.5)$ \\
\hline Cattle 우 $\times$ cattle ơ & 83 & $1^{\mathrm{a}}(1.2)$ & $59^{a}(71.1)$ & $10^{\mathrm{a}}(12.1)$ & $70^{\mathrm{a}, \mathrm{b}}(84.3)$ \\
\hline
\end{tabular}

* PN = Pronucleus. ${ }^{\mathrm{a}, \mathrm{b}}$ Within a column, values without a common superscript are different $(\mathrm{P}<0.05)$.

(FSH) was purchased from Bioniche Life Sciences Inc. (Belleville, Ontario, Canada) and fetal calf serum (FCS) was purchased from Gibco (Grand Island, NY, USA). All other chemicals and reagents used for in vitro maturation (IVM), IVF and in vitro culture (IVC) were cell-culture tested and obtained from Sigma-Aldrich (St. Louis, MO, USA). Synthetic oviductal fluid (SOF) medium without glucose was prepared according to the formula of Tervit et al. [12]. All media were filtered through a $0.2 \mu \mathrm{m}$ Millipore filter (Carrigtwohill, Cork, Ireland) and placed in an incubator (Forma Series II, Waltham, MA, USA) to equilibrate for 4 to $6 \mathrm{~h}$ in an atmosphere of $5 \% \mathrm{CO}_{2}$ in air.

\section{Oocyte collection and IVM}

Collection and IVM of oocytes were as previously described $[11,13]$. Briefly, ovaries were collected from cattle and yaks at local slaughterhouses from October to December and transported, within $3 \mathrm{~h}$, to the laboratory in DPBS (29-33 C). Cumulus-oocyte complexes (COCs) were aspirated from follicles (2-8 mm diameter) using a hand-held 10-ml syringe connected to an 18-gauge needle. COCs were collected in DPBS supplemented with $6 \mathrm{mg} / \mathrm{ml}$ BSA under a low-power (20×) stereomicroscope (Leica MZ16, Germany). The COCs were rinsed three times in DPBS containing $5 \%(\mathrm{v} / \mathrm{v})$ FCS and twice in TCM 199 supplemented with 20\% (v/v) FCS, $5 \mu \mathrm{g} / \mathrm{ml} \mathrm{FSH,} 50 \mathrm{IU} / \mathrm{ml} \mathrm{LH,} 1 \mu \mathrm{g} / \mathrm{ml}$ estradiol- $17 \beta 100 \mathrm{U} / \mathrm{ml}$ penicillin and $100 \mu \mathrm{g} / \mathrm{ml}$ streptomycin (maturation medium). Only COCs having one or more layers of cumulus cells and evenly granulated ooplasm were selected for IVM. Up to 30 COCs were placed in each culture well (Nunc, Naperville IL, USA) containing $600 \mu \mathrm{l}$ of maturation medium covered with mineral oil. COCs were allowed to mature for approximately $24 \mathrm{~h}$ at $38.6 \mathrm{C}$ in an atmosphere of $5 \% \mathrm{CO}_{2}$ in humidified air.

\section{Sperm preparation, IVF and embryo culture}

Sperm preparation for cattle and yak bulls and IVF of oocytes were conducted according to previously described procedures [11, 13] with some modifications. Frozen semen was thawed and washed by centrifugation through a Percoll gradient (30\%/45\%) containing Hepes-buffered SOF medium supplemented with $5 \mathrm{mg} /$ ml BSA, $50 \mu \mathrm{g} / \mathrm{ml}$ caffeine, $30 \mu \mathrm{g} / \mathrm{ml}$ glutathione and $20 \mu \mathrm{g} / \mathrm{ml}$ heparin (sperm medium) and centrifuged at $500 \times g$ for $10 \mathrm{~min}$ to separate motile sperm. After centrifugation, $120 \mu$ l of the concentrated sperm fraction was removed, placed into $200 \mu \mathrm{l}$ of sperm medium and incubated at $38.6 \mathrm{C}$ for $15 \mathrm{~min}$.

After maturation, excess cummulus cells were partially removed by gently swirling the COCs in a 36-mm Petri dish containing SOF with $6 \mathrm{mg} / \mathrm{ml}$ BSA (IVF medium). The COCs were further washed twice in IVF medium before being transferred into 4-well plates (up to 30 per well) containing $500 \mu$ lVF medium covered with mineral oil per well. Sperm were added to produce a final concentration of approximately $1 \times 10^{6}$ motile sperm $/ \mathrm{ml}$. Coincubation was carried out for $24-26 \mathrm{~h}$ at $38.6 \mathrm{C}$ in an atmosphere of $5 \% \mathrm{CO}_{2}$. Remnant cumulus cells were removed from the putative zygotes by gentle pipetting at $26 \mathrm{~h}$ of coincubation. The putative zygotes were then washed three times in SOF medium. Groups of 25 embryos were cultured in $600 \mu \mathrm{l}$ of SOF medium supplemented with $6 \mathrm{mg} /$ $\mathrm{ml}$ BSA, $0.5 \mathrm{mg} / \mathrm{ml}$ myoinositol, 3\% (v/v) essential amino acids, $1 \%(\mathrm{v} / \mathrm{v})$ nonessential amino acids, $100 \mathrm{U} / \mathrm{ml}$ penicillin, $100 \mu \mathrm{g} / \mathrm{ml}$ streptomycin and $100 \mu \mathrm{g} / \mathrm{ml}$ L-glutamine (culture medium) under mineral oil in a humidified atmosphere of $5 \% \mathrm{CO}_{2}, 5 \% \mathrm{O}_{2}$ and $90 \%$ $\mathrm{N}_{2}$ at $38.5 \mathrm{C}[14,15]$. The number of zygotes that cleaved was recorded at $48 \mathrm{~h}$ post insemination (hpi). The culture medium was changed at $96 \mathrm{hpi}$, and blastocyst development was determined on Days 7 to 9 (Day 0: day of insemination).

The presumptive zygotes were randomly examined for evidence of fertilization according to previously described methods [11, 16]. Briefly, at $18 \mathrm{hpi}$, the ova were removed from the culture dish. The cumulus cells and any remaining sperm were completely removed by repeated pipetting in culture medium containing $150 \mathrm{U} / \mathrm{ml}$ of hyaluronidase. The presumptive zygotes were then mounted and placed in fixative (1:3; acetic acid:ethanol) at room temperature for $48-72$ h. They were then stained with $1 \%$ orcein in $45 \%$ acetic acid, cleared with acetyl-glycerol and examined under a phase-contrast microscope at $200 \times$ and $400 \times$ magnification. Oocytes were considered penetrated when one or more pronuclei were observed in the ooplasm.

\section{Statistics}

Penetration, polyspermy and pronuclear formation were analyzed by Chi-square analysis. Percentage data of cleavage and blastocyst rates were subjected to arcsine transformation before analysis by ANOVA, with oocyte species, sperm species and the interaction in the model. Tukey's hsd test was used to determine differences between means. Each experiment was replicated five to seven times.

\section{Results}

\section{Fertilization}

Oocytes from cattle $(n=167)$ and yak $(n=172)$ inseminated with either cattle or yak sperm were examined to determine pronuclear status (Table 1). The formation of one pronucleus, the formation of two pronuclei (normal fertilization) and the incidence of 
Table 2. In vitro development of yak and cattle oocytes inseminated with either yak or cattle spermatozoa*

\begin{tabular}{lccc}
\hline Species combination & $\begin{array}{c}\text { No. oocytes } \\
\text { examined }\end{array}$ & $\begin{array}{c}\text { No. cleaved embryos } \\
(\% ; \text { mean } \pm \text { SEM) }\end{array}$ & $\begin{array}{c}\text { No. blastocysts } \\
(\% ; \text { mean } \pm \text { SEM) }\end{array}$ \\
\hline $\begin{array}{c}\text { Yak oocytes inseminated with } \\
\text { Yak spermatozoa }\end{array}$ & 356 & $233(65.0 \pm 2.4)^{\mathrm{a}, \mathrm{b}}$ & $22 \quad(9.4 \pm 1.8)^{\mathrm{a}}$ \\
$\quad \begin{array}{l}\text { Cattle spermatozoa } \\
\text { Combined }\end{array}$ & 381 & $226(61.1 \pm 2.9)^{\mathrm{a}}$ & $31(13.1 \pm 1.5)^{\mathrm{a}}$ \\
$\begin{array}{c}\text { Cattle oocytes inseminated with } \\
\text { Yak spermatozoa }\end{array}$ & 737 & $459(62.7 \pm 2.0)^{\mathrm{d}}$ & $53(11.5 \pm 1.2)^{\mathrm{d}}$ \\
$\quad$ Cattle spermatozoa & 442 & $318(72.4 \pm 2.2)^{\mathrm{b}}$ & $109(36.5 \pm 3.6)^{\mathrm{b}}$ \\
Combined & 470 & $312(67.0 \pm 1.9)^{\mathrm{a}, \mathrm{b}}$ & $78(25.2 \pm 4.1)^{\mathrm{c}}$ \\
\hline
\end{tabular}

* Five to seven replicated trials were carried out, and blastocysts were harvested on Day 9. Blastocyst formation rate was calculated from the cleaved zygotes. ${ }^{\mathrm{a}-\mathrm{c}}$ Within a column, values without a common superscript are different $(\mathrm{P}<0.05)$. ${ }^{\mathrm{d}, \mathrm{e}}$ Values for main effect least-squares means without common superscripts differ $(\mathrm{P}<0.05)$.

polyspermy ( $>2$ pronuclei) did not differ among the four combinations of fertilization. The percentage of IVM oocytes penetrated by spermatozoa ranged from 78.5 to $90.5 \%$ across the treatment groups. The percentage of cattle oocytes penetrated by spermatozoa from yak was greater $(\mathrm{P}<0.05)$ than that of yak oocytes penetrated by cattle spermatozoa, but the percentage of yak oocytes penetrated by spermatozoa from yak did not differ compared with those penetrated by cattle spermatozoa.

\section{Cleavage and early embryo development}

Cleavage at 48 hpi was not affected by the species of the sperm (Table 2), but it was clearly affected by the species of the oocytes $(\mathrm{P}<0.05)$, with cattle oocytes $(69.9 \%)$ having a higher $(\mathrm{P}<0.05)$ cleavage rate than yak oocytes (62.7\%). There was no sire species $\times$ oocyte species interaction. The percentage of yak oocytes cleaving after insemination with cattle spermatozoa (61.1\%) was similar to that of yak oocytes inseminated with yak spermatozoa (65.0\%).

The overall blastocyst production rate was not affected by the species of the sperm, but it was clearly affected by the species of the oocytes ( $\mathrm{P}<0.05$; Table 2$)$, with cattle oocytes (31.3\%) having a greater $(\mathrm{P}<0.05)$ blastocyst yield than yak oocytes $(11.5 \%)$. The blastocyst yield was higher $(\mathrm{P}<0.05)$ for purebred cattle embryos than for purebred yak embryos (25.2 vs. 9.4\%). Furthermore, there was a sire species $\times$ oocyte species interaction $(P<0.05)$, with the highest blastocyst yield being obtained for cattle oocytes fertilized with yak spermatozoa (36.5\%) and the lowest yield being obtained for the homologous yak combination (9.4\%). The critical comparison was that of the purebred versus the crossbred embryos - the blastocyst rate was 7.5\% higher in the latter (9.4 and 25.2\% vs. 13.1 and $36.5 \%)$.

\section{Discussion}

Many studies have shown that pregnancy rates are above $70 \%$ if female yak are mated with yak bulls $[1,5,17,18]$. However, when the yak female is inseminated (naturally or artificially) with semen from Bos taurus or Bos indicus, the pregnancy rate falls [3, 5]. It has long been suspected that this reduction results, at least partly, from species-specific sperm-egg interactions that ultimately affect heterologous fertilization and early embryo development. How- ever, in this study, the rate of fertilization as assessed by the formation of pronuclei did not differ when yak and cattle oocytes were inseminated with either yak or cattle spermatozoa. These results are in agreement with those reported in previous studies showing that cattle oocytes can be fertilized with sperm from the oryx [19, 20], yak [9, 11], bison, banteng and gaur [9], suggesting little cross-species specificity with regard to gamete interaction among Bovidae. Thus, penetration failure and/or abnormal fertilization are not the main factors that contribute to poor conception rates when female yaks are crossed with cattle.

Oocytes obtained from cattle were more likely to cleave and develop to the blastocyst stage after in vitro maturation and fertilization than oocytes from yak. The intrinsic quality of the oocytes is thought to be of critical importance in determining the developmental outcome [21-25]; any deficiency in yak oocytes might reflect coincidental changes in cytoplasmic and/or nuclear components that are related to the evolving adaptability of the yak in their unique environment. We cannot dismiss the involvement of extrinsic factors in the results. The yak oocytes in the present study were obtained at the end of the breeding season, and seasonal conditions may have impaired oocyte competence. The lower development of yak embryos might also be related to the culture system, which has been developed specifically for use in cattle. Oliveira-Filho et al. [26] and Fischer et al. [27] attributed lower blastocyst formation rates in $B$. indicus to the greater compatibility of the culture system with $B$. taurus gametes. Also, the blastocyst rates of yak hybrid embryos observed in this study were much greater than those reported in previous studies $[9,10]$.

The most significant finding in this study was that the cleavage rates for heterologous IVF of yak and cattle gametes were comparable to those achieved with homologous yak IVF, and the blastocyst rate for yak oocytes fertilized with cattle spermatozoa was not significantly different from that for homologous yak IVF. Thus, it is likely that the lower conception rates that occur when female yaks are crossed with cattle are not due to the developmental competence of early stage embryos. To our knowledge, this is the first time this has been reported in this field.

Interestingly, hybrid embryos of the yak and cattle had a significant heterosis for blastocyst yield with a large difference occurring between reciprocal crosses. Individual bulls effects in IVF might 
have contributed to these differences [15, 24], but our previous work also showed that the blastocyst yield of cattle oocytes fertilized with yak spermatozoa was greater than for homologous cattle IVF [11]. Such heterosis has also been reported in gilts [28], B. taurus $\times B$. indicus [29] and $B$. taurus [30,31], although in another study [27], no evidence of heterosis was found for crosses within $B$. taurus breeds or between $B$. taurus and B. indicus. The cause of this discrepancy is not clear, but it is possible that breed maternal effects can influence outcome [32]. The results of the present study also indicate that this reciprocal difference occurs at fertilization and during early cleavage development in vitro.

In conclusion, the cleavage rates of heterologous and homologous IVF were not significantly different. The blastocysts derived from yak oocytes fertilized either with yak or cattle spermatozoa were also not significantly different. The blastocyst rate obtained from cattle oocytes fertilized with either cattle or yak spermatozoa was significantly higher than those from yak oocytes fertilized with either yak or cattle spermatozoa. The results from this study showed that the low conception rate after mating yak females with cattle bulls does not correlate with the species specific block of fertilization or developmental competence of the early stage embryos.

\section{Acknowledgements}

We thank Dr. S Walker, Embryo Technologies Pty Ltd, Adelaide, South Australia, for his technical assistance and critical reading of the manuscript. This research was funded by the Science and Technology Bureau of Sichuan Province (No. 07JY029-128), and the Personnel Bureau of Sichuan Province, PR China.

\section{References}

1. Wiener G, Han JL, Long RJ. The Yak. Bangkok: The Regional Office for Asia and the Pacific of the Food and Agriculture Organization of the United Nations; 2003.

2. Zi XD, Zhong GH, Wen YL, Zhong JC, Liu CL, Ni YA, Yezi YH, Ashi MG. Growth performance, carcass composition and meat quality of Jiulong-Yak (Bos grunniens). Asian-Aust J Anim Sci 2004; 17: 410-414.

3. Cai $\mathbf{L}$. The research on the interspecific cross combination between female yak and Bos taurus bull. In: Liu XM (ed.), The Research on the Utilization and Exploitation of Grassland in the Northwestern Part of Sichuan Province. Chengdu: National Publishing House of Sichuan; 1984: 107-113 (In Chinese).

4. Katzina EV, Davydov VN, Baldanov ND. Elaboration of the scheme of production and usage of industrial hybrids of yak and meat cattle. In: Proc 1st Int Cong on Yak; Lanzhou, China, 1994: 44-48.

5. Zi XD, He SM, Lu H, Feng JA, Lu JY, Chang S, Wang X. Induction of estrus in suckled female yaks (Bos grunniens) and synchronization of ovulation in the non-sucklers for timed artificial insemination using progesterone treatments and Co-Synch regimens. Anim Reprod Sci 2006; 92: 183-192.

6. Hwang WS, Jo CH, Lee BC, Shin TY, Kim KS, Roh SH, Kim SK, Chun BC, Lee KN, Shin OI, Yim HS. Successful calving following transfer of bovine embryos produced by in vitro fertilization in Korea. J Reprod Dev 1995; 41: 175-179.

7. Suzuki C, Iwamura S, Yoshioka K. Birth of piglets through the non-surgical transfer of blastocysts produced in vitro. J Reprod Dev 2004; 50: 487-491.

8. Cognié Y, Baril YG, Poulin N, Mermillod P. Current status of embryo technologies in sheep and goat. Theriogenology 2003; 59: 171-188.

9. McHugh JA, Rutledge JJ. Heterologous fertilization to characterize spermatozoa of the genus Bos. Theriogenology 1998; 50: 185-193.
10. Xu ZB. Early embryonic development of crossbreeding between yak and cattle in vitro. M.Sc. Dissertation. Lanzhou: Institute of Anim Vet Pharmacol Sci 2006 (In Chinese).

11. Zi XD, Lu H, Yin RH, Chen SW. Development of embryos after in vitro fertilization of bovine oocytes with sperm from either yaks (Bos grunniens) or cattle (Bos taurus). Anim Reprod Sci 2008; 108: 208-215.

12. Tervit HR, Whittingham DG, Rowson LEA. Successful culture in vitro of sheep and cattle ova. J Reprod Fertil 1972; 30: 493-497.

13. Parrish JJ, Susko-Parrish JL, Critser ES, Eyestone WH, First NL. Bovine in vitro fertilization with frozen-thawed semen. Theriogenology 1986; 25: 591-600.

14. Ikeda S, Azuma T, Hashimoto S, Yamada M. In vitro maturation of bovine oocytes with fractions of bovine follicular fluid separated by heparin affinity chromatography. J Reprod Dev 1999; 45: 397-404.

15. Zhang M, Lu KH, Seidel JGE. Development of bovine embryos after in vitro fertilization of oocytes with flow cytometrically sorted, stained and unsorted sperm from different bulls. Theriogenology 2003; 60: 1657-1663.

16. Kouba AJ, Atkinson MW, Gandolf AR, Roth TL. Species-specific sperm-egg interac tion affects the utility of a heterologous bovine in vitro fertilization system for evaluating antelope sperm. Biol Reprod 2001; 65: 1246-1251.

17. Yu SJ, Huang YM, Chen BX. Reproductive patterns of the yak. I. Reproductive phenomena of the female yak. Br Vet J 1993; 149: 579-583.

18. Zi XD. Reproduction in female yaks (Bos grunniens) and opportunities for improvement. Theriogenology 2003; 59: 1303-1312.

19. Roth TL, Weiss RB, Buff JL, Bush LM, Wildt DE, Bush M. Heterologous in vitro fertilization and sperm capacitation in an endangered African antelope, the Scimitarhorned oryx (Oryx dammah). Biol Reprod 1998; 58: 475-482.

20. Roth TL, Bush LM, Wildt DE, Weiss RB. Scimitar-horned oryx (Oryx dammah) spermatozoa are functionally competent in a heterologous bovine in vitro fertilization system after cryopreservation on dry ice, in a dry shipper, or over liquid nitrogen vapor. Biol Reprod 1999; 60: 493-498.

21. Revel F, Mermillod P, Peynot N, Renard JP, Heyman Y. Low developmental capacity of in vitro matured and fertilized oocytes from calves compared with that of cows. Reprod Fertil 1995; 103: 115-120.

22. Rocha A, Randel RD, Broussard JR, Lim JM, Blair RM, Roussel JD, Godke RA, Hansel W. High environmental temperature and humidity decrease oocyte quality in Bos taurus but not in Bos indicus cows. Theriogenology 1998; 49: 657-665.

23. de Wit AAC, Wurth YA, Kruip ThAM. Effect of ovarian phase and follicle quality on morphology and developmental capacity of the bovine cumulus-oocyte complex. J Anim Sci 2000: 78: 1277-1283.

24. Ward F, Rizos D, Corridan D, Quinn K, Boland M, Lonergan P. Paternal influence on time of first embryonic cleavage post insemination and the implications for subsequent bovine embryo development in vitro and fertility in vivo. Mol Reprod Dev 2001; 60: 47-55.

25. Camargo LSA, Viana JHM, Ramos AA, Serapiao RV, de Sa WF, Ferreira AM Guimaraes MFM, do Vale Filho VR. Developmental competence and expression of the Hsp 70.1 gene in oocytes obtained from Bos indicus and Bos taurus dairy cows in a tropical environment. Theriogenology 2007; 68: 626-632.

26. Oliveira-Filho EB, Catt J, Garcia JM, Esper CR. "In vitro" fertilization in zebu cattle (Bos indicus): Some peculiarities affecting early development. Proc 4th World Cong On Genet Applied to Livest Prod 1994; 12, 1330-1332.

27. Fischer AE, Bernal DP, Gutierrez-Robayo C, Rutledge JJ. Estimates of heterosis for in vitro embryo production using reciprocal crosses in cattle. Theriogenology 2000; 54 $1433-1442$.

28. Irgang R, Scheid IR, Wentz I, Favero JA. Ovulation rate, embryo number and uterus length in purebred and crossbred Duroc, Landrace, and Large White gilts. Livestock Prod Sci 1993; 33: 253-266.

29. Armas RD, Solano R, Riego E, Pupo CA, Aguilar A, Ramos B, Aguirre A, Fuente JDL, Castro FO. Use of F1 progeny of Holstein $\times$ Zebu cross cattle as oocyte donors for in vitro embryo production and gene microinjection. Theriogenology 1994; 42: 977-985.

30. Hamano S, Koikeda A. Developmental capacity of F1 hybrid embryos produced by in vitro fertilization between different breeds Japanese beef cattle. J Reprod Dev 1995; 41 149-152.

31. Boediono A, Suzuki T, Godke RA. Comparison of hybrid and purebred in vitroderived cattle embryos during in vitro culture. Anim Reprod Sci 2003; 78: 1-11.

32. Anderson GB. Interspecific pregnancy: barriers and prospects. Biol Reprod 1998; 38: 115. 